\title{
THE EFFECT OF HYPNOTHERAPY AND MENTAL TOUGHNESS ON CONCENTRATION WHEN COMPETING FOR FUTSAL ATHLETES
}

\author{
Rachmi Marsheilla Aguss ${ }^{1 *}$, Rizki Yuliandra ${ }^{1}$ \\ ${ }^{1}$ Pendidikan Olahraga, Fakultas Sastra dan Ilmu Pendidikan, Universitas Teknokrat Indonesia, Jl. Z. A. Pagar \\ Alam No 9-11, Labuhan Ratu, Kedaton, Bandar Lampung, Lampung, Indonesia. \\ Rachmi.ma@teknokrat.ac.id, rizki.yuliandra@teknokrat.ac.id
}

\begin{abstract}
The purpose of this study was to determine the difference in the effect of the type of hypnosis and the level of mental toughness on the concentration of futsal athletes. This research method is experimental. Types of hypnotherapy that are done are hypnosis and self-hypnosis. The data collection technique used a questionnaire, the variable measured mental toughness was low and a little low using, questionnaire and hypnotherapy treatment with 6 meetings with a duration of 30-60 minutes, grouping the level of mental toughness was obtained after pretesting the results of the questionnaire. The data analysis technique was two way anava with SPSS 16. The subjects of the research were 16 male futsal athletes. The significance level is 0.05 . The results showed that there were differences in the effect of hypnosis and self-hypnosis on the athlete's concentration, the significance value $=0.013$, meaning that there was an effect. There is no difference in the effect of low and rather low mental toughness on the athlete's concentration, the significance value $=0.130$ means there is no effect. There is no interaction between mental toughness and hypnotherapy on the athlete's concentration, the significance value $=0.635$ means mental toughness and hypnotherapy do not interact. The conclusions of the study are getting the differences in the treatment of hypnosis and selfhypnosis, knowing the differences in the effect of mental toughness, and knowing the interaction between hypnotherapy and mental toughness. The advice is that athletes have good mental toughness and self-control, believe in their own abilities. Coaches support athletes by providing coaching that can improve mental toughness and concentration.
\end{abstract}

Keywords: Hypnotherapy, Concentration, Mental Thougness, Hypnosis, Self Hypnosis.

\section{PENGARUH JENIS HIPNOTERAPI DAN TINGKAT KETANGGUHAN MENTAL TERHADAP KONSENTRASI ATLET FUTSAL}

\begin{abstract}
Abstrak
Tujuan dari penelitian ini adalah untuk mengetahui perbedaan pengaruh jenis hipnosis dan tingkat ketangguhan mental terhadap konsentrasi atlet futsal. Metode penelitian ini eksperimen. Jenis hipnoterapi yang dilakukan adalah hipnosis dan self-hipnosis. Teknik pengumpulan data menggunakan angket, variabel yang diukur ketangguhan mental rendah dan agak rendah dengan menggunakan angket ketangguhan mental dan treatment hypnotherapy dengan 6 peretemuan durasi 30-60 menit, pengelompokkan tingkat ketangguhan mental diperoleh setelah diadakan pretest hasil dari angket tersebut. Teknik analisis data two way anava dengan program SPSS 16. Subjek penelitian atlet futsal putra berjumlah 16 orang. Taraf signifikasi 0,05 . Hasil penelitian yaitu ada perbedaan pengaruh hipnosis dan self-hypnosis terhadap konsentrasi atlet, nilai signifikansi $=0,013$, artinya ada pengaruh. Tidak ada perbedaan pengaruh ketangguhan mental rendah dan agak rendah terhadap konsentrasi atlet nilai signifikansi $=0,130$ berarti tidak ada pengaruh. Tidak ada interaksi antara ketangguhan mental dan hipnoterapi terhadap konsentrasi atlet, nilai signifikansi $=0,635$ artinya ketangguhan mental dan hipnoterapi tidak berinteraksi. Simpulan penelitian yaitu mendapatkan
\end{abstract}


perbedaan perlakuan hipnosis dan self-hipnosis, diketahuinya perbedaan pengaruh ketangguhan mental, dan diketahuinya interaksi antara hipnoterapi dan ketangguhan mental. Sarannya atlet memiliki ketangguhan mental dan kontrol diri yang baik, percaya pada kemampuan sendiri. Pelatih mendukung atlet dengan memberikan pembinaan yang dapat meningkatkan ketangguhan mental dan konsentrasi.

Kata kunci : Hipnoterapi, Konsentrasi, Ketangguhan Mental, Hipnosis, Self-Hipnosis.

\section{PENDAHULUAN}

Untuk mencapai prestasi yang maksimal diperlukan adanya pembinaan atlet yang selaras, serasi dan seimbang antara mental dan fisik. Untuk meningkatkan kemampuan teknik, fisik, dan taktik, apabila tidak disertai dengan pembinaan mental yang bagus, maka akan menghasilkan sesuatu yang negatif. Suatu daya pendorong dan penggerak demi penguatan keterampilan teknik, taktik dan fisik bagi penampilan olahraga adalah mental. Dalam (Purnama, 2016) mengatakan bahwa tiap kali menjalani event pertandingan, mental atlet wajib disiapkan dengan matang, baik siap untuk melawan impuls penuh emosi, siap menanggung tanggung jawab yang hebat atau dengan kata lain siap menghadapi beban mental.

Tim futsal putra Universita Teknokrat Indonesia merupakan salah satu tim yang diunggulkan para mahasiswa di Lampung. Pertandingan Pekan Olahraga Mahasiswa Daerah (POMDA) Futsal 2019 pada tanggal 20-24 Maret yang lalu, team futsal putra tidak dapat memperoleh satu kemenangan. Perolehan kemenangan team futsal putra hanya sampai perempat final saja. Faktor yang menyebabkkan tim tidak memperoleh kemenangan salah satu nya adalah kurangnya performa para atlet putra selama pertandingan yang telah mereka lalui. Tingkat performa tim tersebut sangat rendah bila dibandingkan dengan 9 tim lainnya yang berlaga pada pertandingan tersebut.

Dalam menjalankan proses latihan sehari-hari yang telah dijadwalkan, terlihat para atlet futsal putra dalam keadaan baik-baik saja ketika berada didalam lapangan. Akan tetapi, selama pertandingan didapatkan bahwa rata-rata atlet mengalami gugup, telapak tangan menjadi keringat dingin, gemetar dan jantung atlet berdebar saat akan memasuki arena pertandingan, mengimajinasikan tim lawan yang akan bertemu di arena pertandingan oleh tim bisa jadi jauh lebih tangguh, memperkirakan berapa nanti hasil yang akan didapatkan, ketika atlet melakukan kesalahan, sikap yang sering mereka terima seperti sorak-sorai atau kata-kata kasar yang keluar dari para penonton membuat atlet menjadi down atau mental turun secara psikis, yang berakibat dapat mengganggu konsentrasi atlet saat bertanding setelah dilakukan survei dan wawancara pada saat sesi latihan.

Berikut prestasi atlet futsal putra Universitas Teknokrat Indonesia dari tahun 2014 sampai dengan 2019. Pada Tahun 2014 pertandingan yang diikuti diantaranya kejuaraan business futsal competition meraih juara 2, physics futsal competition meraih juara 1, dan kejuaraan chemical enginerering futsal competition mendapatkan juara 2. Ditahun 2015, kejuaraan yang diikuti yaitu kejuaraan futsal tingkat kopertis meraih juara 2, kejuaraan business futsal competition juara 3, dan UBL futsal competition meraih juara 2. Tahun 2016, kejuaraan futsal tingkat kopertis meraih juara 2. Tahun 2017 mengikuti kejuaraan futsal tingkat kopertis juara 2, dan kejuaraan pomda juara 1 dan 2. Tahun 2018 mengikuti kejuaraan persiteracup tidak menjadi juara. Terakhir kejuaraan poltekes cup meraih juara 2.

Pengamatan peneliti pada pertandingan Pekan Olahraga Mahasiswa Daerah (POMDA) pada saat atlet futsal Universitas Teknokrat Indonesia melawan tim futsal dari Universitas Lampung. Terlihat kekalahan disebabkan karena seringnya atlet melakukan kesalahan saat melakukan transisi atau peralihan strategi dari ofensif ke defends sehingga 
selalu mendapatkan serangan balik yang berbahaya pada team putra. Pola penyerangan atau disebut juga dengan ofensif. Dan defens adalah kemampuan dalam mempertahankan atau menangkis serangan dari lawan. Pentingnya untuk memperhatikan mental saat bertanding yaitu jika seorang atlet mengalami rasa gelisah yang bisa dibilang tinggi, dan tingkat konsentrasi mengalami penurunan dapat mengakibatkan sang atlet merasa sulit untuk mengatur gerakan, main dalam hal ini bertanding menjadi tidak bagus, gagal untuk menggunakan strategi yang dirancang sebab tidak memahami akan melakukan apa hingga pada nantinya bisa mempengaruhi performa atlet, rasa tidak percaya diri jadi rendah sampai ada yang merasa rasa percaya dirinya hilang. Maka dari itu pentingnya suatu metode atau cara yang bisa menyokong seorang atlet demi meminimalisasi merendahnya mental dan mampu menumbuhkan konsentrasi yaitu dengan memakai hipnoterapi sebagai metode.

Berikut ini merupakan contoh penelitian mutakhir yang mempunyai relevans terhadap penelitian ini, tentang masalah, nilai, dan, inovasi. Penelitian yang relevan dapat di jadikan sebagai rujukan untuk pengembangan penelitian yang baru terkait dengan tema dan atau pokok bahasan yang sama. Penelitian yang memiliki relevansi antara lain sebagai berikut..

Penelitian yang relevan dilakukan oleh (Maheswari, 2019) berdasarkan dari hasil analisis data pada penelitian yang dilakukan melalui pengujian statistik dengan judul hubungan antara ketangguhan mental dengan peak performance menghasilkan bahwa terdapat hubungan positif yang signifikan antara ketangguhan mental dengan peak performance pada atlet taekwondo. Hasil dari peneliti tersebut dijelaskan untuk komponen ketangguhan mental dan peak performance berhubungan signifikan positif. Jika ketangguhan mental pada atlet tinggi, maka peak performance nya juga tinggi. Sebaliknya, jika ketangguhan mental pada atlet rendah, maka peak performance nya juga rendah. Didalam (Ardini \& Jannah, 2017) orang yang melakukan latihan dan terus berlatih agar mendapatkan kekuatan badan, daya tahan, kecepatan, kelincahan, keseimbangan, kelenturan dan kekuatan dalam mempersiapkan diri jauh-jauh hari sebelum pertandingan dimulai disebut dengan atlet. Atlet yang tidak memiliki konsentrasi yang baik dan hal tersebut berdampak pada penampilan yang akan menurun drastis merupakan atlet yang tidak mampu mengelola berbagai tekanan yang menimpa dirinya berarti (menurut Komaruddin didalam (Bolla et al., 2018).

Menurut Roeslan Hatta permainan futsal adalah sepak bola mini yang dipertandingkan dalam sebuah ruangan dengan panjang lapangan 38 sampai 42 meter dan lebar 15 sampai 25 meter. Futsal adalah permainan bola yang dimainkan secara cepat dengan segi lapangan kecil dalam Justinus Lhaksana. Permainan sepak bola dalam olahraga dengan ukuran gawang dan juga lapangan nya yang agak kecil yang dimainkan dengan 5 orang pemain adalah pengetian futsal menurut Dendy Sugono. Olahraga yang sedikit mirip dengan sepak bola dikenal dengan nama olahraga futsal. Olahraga futsal merupakan olahraga yang berintensitas tinggi yang ditandai dengan adanya aktivitas berlari secara berulang- ulang dengan waktu yang relatif lama (Sa'roni \& Graha, 2019). Begitu juga dengan tekniknya, cara dalam menggiring bola, saat menendang bola, dan pada saat menghentikan bola. Pada umumnya permainan cabang olahraga futsal hampi memiliki kesamaan dengan permainan sepak bola, yang membutuhkan daya tahan tubuh yang baik, juga memiliki strategi dan mental yang baik pula. Akan tetapi terdapat perbedaan sedikit dalam hal pola permainan dan penyerangan (Lhaksana, 2011). Permainan bola yang dimainkan oleh dua regu dengan 5 anggota disetiap regu dengan tujuan memasukkan bola ke gawang lawan merupakan ciri dari permainan futsal. (Halim, 2012) Sangat penting pada usia anak-anak dalam pengembangan kualitas mereka dan pemahaman terhadap pada permainan. Permainan futsal merpakan sejenis permainan sepak bola yang dimainkan dalam lapangan yang berukuran kecil. Pada tiapregu nya memiliki 
pemain cadangan diluar dari lima pemain inti. Tidak seperti permainan sepak bola dalam ruangan lainnya, lapangan futsal dibatasi garis. Tujuannya adalah memasukkan bola ke gawang lawan. Dengan memanipulasi bola dengan kaki. Kata futsal berasal dari bahasa Spanyol, yaitu Futbal (sepak bola) dan Sala (ruangan) yang jika digabung artinya menjadi "sepak bola dalam ruangan".

Didalam Hasibuan (2016), keterampilan bermain futsal itu sendiri menjadi salah satu hal yang penting dan salah satu faktor yang paling utama dalam permainan futsal selain untuk menyerang dan mencetak gol. Keterampilan juga untuk bertahan atau deffens yaitu untuk menjaga agar gawang tidak kebobolan lawan. Sasaran dari setiap tim adalah mencetak gol ke gawang lawan. Suatu tim dapat dikatakan menang adalah jika tim mampu mencetak gol ke gawang tim lawan maksimal dan pada kebobolan dari lawan lebih sedikit dibandingkan dengan lawan. Gunarsa, 2012, suatu keadaan fokus, tenang, dan rileks sehingga dapat mencerna informasi atau sugesti yang masuk ke dalam pikiran disebut hipnosis. Lengkap, pada situasi dan keadaan kapan pun, dimana pun dan bagaimana pun seketika pikiran kita fokus, rileks, maka saat pula terjadi keadaan yang disebut dengan hipnosis. Kata hipnosis diambil dari nama dewa Yunani yang bernama "hypnoz" dan pertama kali diperkenalkan oleh seorang dokter yang bernama James Braid. Hipnosis adalah keadaan seperti tidur karena sugesti, yang pada taraf permulaan orang itu berada dibawah pengaruh orang yang memberikan sugesti, tetapi pada taraf berikutnya menjadi tidak sadar sama sekali menurut Kamus Besar Bahasa Indonesia (https://kbbi.web.id/hipnotis). Gunarsa juga menjelaskan bahwa "konsentrasi merupakan kemampuan yang sangat penting agar perhatian menjadi terpusat terhadap permainan dengan berbagai lika-likunya, serta terhadap taktik atau strategi untuk bermain sebaik-baiknya". Dari pernyataan diatas maka didapatkan inti sari mengenai konsentrasi ialah terkait aktifitas pada pemusatan perhatian, terdapat objek yang perlu diperhatikan, mempunyai rentang waktu tersendiri, juga memiliki kesempatan untuk mempengaruhi jalan nya aktifitas dan efek perilaku. Konsentrasi yang penuh akan mampu kita dapatkan jika kita fokus pada suatu perhatian merupakan dasar dari konsentrasi. Gangguan sulit berkonsentrasi atau gangguan pemusatan perhatiahn (GPP) adalah suatu gangguan pada otak yang mengakibatkan kesuiitan konsentrasi dan pemusatan perhatian (Alim, 2015). Pikiran kita menjadi terbagi dan yang paling parah biasanya kita memfokuskkan perhatian kita pada masalah itu, itu adalah keadaan disaat kita sedang mempunyai banyak masalah.

Supriyanto, (2011) mengemukakan bahwa metode hipnoterapi merupakan cara hipnosis yang ratusan tahun lalu telah digunakan, hingga sampai sekarang cara dan teknik yang paling aktual dalam hipnotisme berkembang pesat dinegara maju demi menolong orang-orang ketika mengatasi banyak hal permasalahan psikologi dan fisik termasuk pada aspek olahraga. Dijelaskan bahwa hipnoterapi memiliki pengaruh yang positif terhadap parameter kekebalan tubuh, dengan data terhadap ekspresi T-Cellinterferon-gamma dan interleukin-2, mengurangi tanda inflamasi, seperti tingkat sedimentasi eritrosit, $C$-Creative protein, meningkatkan secretory immunoglobulin-A, meningkatkan neurtrophill adherence dan aktivitas leukosit pengaruh hipnoterapi dapat memodulasi aliran darah otak menurut Keefer didalam (Sartono et al., 2020).

Tujuan Penelitian ini yang pertama yaitu untuk mendapatkan perbedaan pengaruh perlakuan hipnosis dan perlakuan self-hypnosis terhadap konsentrasi atlet futsal putra. Tujuan yang kedua yaitu untuk mengetahui perbedaan pengaruh antara ketangguhan mental yang rendah dan sangat rendah terhadap konsentrasi pada atlet futsal putra. Tujuan yang ketiga yaitu untuk mengetahui interaksi antara perlakuan hipnoterapi dan ketangguhan mental terhadap konsentrasi pada atlet futsal putra. Sedangkan untuk manfaat penelitian ini agar dapat memberi informasi ilmiah untuk mengembangkan ilmu pengetahuan, terkhusus bagi 
pembinaan dan pelatihan olahraga futsal Universitas Teknokrat Indonesia tentang pengaruh perlakuan hipnoterapi dan ketangguhan mental terhadap konsentrasi saat bertanding pada atlet futsal putra Universitas Teknokrat Indonesia.

\section{METODE}

Penelitian ini menggunakan metode eksperimen dengan model eksperimen desain faktorial $2 \times 2$. Eksperimen faktorial dalam penelitian ini memperhatikan kemungkinan adanya interaksi antara ketiga variabel. Penelitian ini dilaksanakan di gedung Indoor Universitas Teknokrat Indonesia. Populasi penelitian adalah atlet putra Futsal Universitas Teknokrat Indonesia berjumlah 16 atlet. Didalam penelitian ini memakai teknik sampling dengan total sampling dimana seluruh anggota populasi dijadikan sampel. Artinya sampel dalam penelitian ini 16 atlet yang meliputi 8 sampel menggunakan perlakuan hipnosis (terdiri dari 2 kelompok) dan 8 sampel menggunakan perlakuan self-hipnosis (terdiri dari 2 kelompok) dengan per kelompok 4 sampel. Konsentrasi diukur dengan Model Grid Concentrasion Test. Analisis data dalam penelitian ini dengan memakai perhitungan Two Way Anova yang didalamnya terdapat uji prasyarat analisis uji normalitas dan homogenitas. Berikut desain faktorian $2 \times 2$.

Tabel 1. Desain Faktorial 2x2

\begin{tabular}{lll}
\hline \multirow{2}{*}{$\begin{array}{l}\text { Ketangguhan } \\
\text { Mental (B) }\end{array}$} & \multicolumn{2}{c}{ Hipnoterapi (A) } \\
\cline { 2 - 3 } & Hipnosis $\left(\mathrm{A}_{1}\right)$ & Self-Hypnosis $\left(\mathrm{A}_{2}\right)$ \\
\hline Rendah $\left(\mathrm{B}_{1}\right)$ & $\mathrm{A}_{1} \mathrm{~B}_{1}$ & $\mathrm{~A}_{2} \mathrm{~B}_{1}$ \\
Agak Rendah $\left(\mathrm{B}_{2}\right)$ & $\mathrm{A}_{1} \mathrm{~B}_{2}$ & $\mathrm{~A}_{2} \mathrm{~B}_{2}$ \\
\hline
\end{tabular}

Keterangan :

A : Hypnoterapy

B : Ketangguhan Mental

$\mathrm{A}_{1} \quad$ : Hypnosis

$\mathrm{A}_{2} \quad$ : Self-Hypnosis

$\mathrm{B}_{1} \quad$ : Rendah

$\mathrm{B}_{2} \quad$ : Agak Rendah

$\mathrm{A}_{1} \mathrm{~B}_{1}$ : adalah treatment hipnosis dengan ketangguhan mental rendah

$\mathrm{A}_{2} \mathrm{~B}_{1} \quad$ : adalah treatment self-hypnosis dengan ketangguhan mental rendah

$\mathrm{A}_{1} \mathrm{~B}_{2} \quad$ : adalah treatment hipnosis dengan ketangguhan mental agak rendah

$\mathrm{A}_{2} \mathrm{~B}_{2}$ : adalah treatment self-hypnosis dengan ketangguhan mental agak rendah

Desain penelitian ini menggambarkan terdapat satu kelompok yang diberikan treatmen hipnosis dan satu kelompok lagi diberikan treatmen self-hypnosis, namun sebelum diberi perlakuan atau treatment dilakukan tes awal (pre test) terlebih dahulu yang menggunakan instrumen berupa angket ketangguhan mental dan modul grid concentration exercise. Sebelumnya angket telah diuji validasi oleh expert yaitu ahli hipnoterapi dan pelatih futsal Universitas Teknokrat Indonesia. Setelah diberikan pre test, dapat ditentukan atlet masuk ke dalam kelompok hypnosis atau self-hypnosis dilakukan menggunakan ordinal pairing dengan sistem ABBA berdasarkan kelompok yang telah dibagi dan diberikan treatment selama $6 \mathrm{x}$ ulasan, tes akhir (post test) yang diberikan pada sampel berupa angket dan modul grid concentration lagi. Dengan demikian hasil dari perlakuan dapat diperoleh hasil yang sahih, yang nanti dapat dilihat perbedaan dari keadaan sebelum diberi perlakuan dan sesudah diberi perlakuan. 
MEDIKORA, Vol. 20 No. 1 April 2021 - 58

Rachmi Marsheilla Aguss, Rizki Yuliandra

Tabel 2. Klasifikasi Tingkat Ketangguhan Mental

\begin{tabular}{ccccc}
\hline & \multicolumn{4}{c}{ Tingkat Kecemasan } \\
\hline Skala Kecemasan & Tinggi & Agak Tinggi & Agak Rendah & Rendah \\
\cline { 2 - 5 } Olahraga & $1-26$ & $27-50$ & $51-74$ & $75-100$ \\
\hline
\end{tabular}

Pengumpulan data dalam penelitian ini menggunakan teknik yang pertama diberikan yaitu pelaksanaan tes awal sebelum peneliti memberikan perlakuan kepada sampel untuk mengetahui ketangguhan mental dan konsentrasi atlet, sedangkan tes akhir dilaksanakan setelah sampel mendapat perlakukan atau treatment. Pemberian perlakukan (treatment) pada sampel dalam penelitian dilakukan menggunakan treatment hypnosis untuk kelompok pertama dan menggunakan treatment self-hypnosis untuk kelompok kedua. Perlakuan diberikan selama 3 bulan.

Akan menggunakan teknik analisis varian (ANAVA) dalam pengujian hipotesis, rancangan faktorial $2 \times 2$ dengan taraf signifikan $\alpha=0,05$. Dalam penelitian ini terdapat variabel terikat, variabel bebas, dan variabel kontrol. Yang menjadi variabel terikat yaitu konsentrasi, variabel bebas penelitian ini yaitu treatment hipnoterapi, dan variabel kontrol nya yaitu ketangguhan mental yang dibedakan menjadi ketangguhan mental rendah dan agak rendah. Syarat untuk melakukan analisis varian yaitu uji normalitas data dengan memakai pengujian shapiro wilk dan pengujian Levene untuk uji homogenitas menggunakan SPSS 16.

Tabel 3. Program pelaksanaan pemberian treatment

\begin{tabular}{ccll}
\hline Ulasan Ke & Tanggal & \multicolumn{1}{c}{$\begin{array}{c}\text { Perlakuan yang } \\
\text { diberikan }\end{array}$} & Waktu \\
\hline 1 & 4 Maret 2020 & Melakukan pre test & 30 menit \\
2 & 8 April 2020 & Pemberian treatment & 90 menit \\
3 & 22 April 2020 & Pemberian treatment & 90 menit \\
4 & 6 Mei 2020 & Pemberian treatment & 90 menit \\
5 & 20 Mei 2020 & Pemberian treatment & 90 menit \\
6 & 10 Juni 2020 & Pemberian treatment & 90 menit \\
7 & 24 Juni 2020 & Pemberian treatment & 90 menit \\
8 & 8 Juli 2020 & Melakukan Post test & 30 menit \\
\hline
\end{tabular}

\section{HASIL DAN PEMBAHASAN}

Dari penelitian yang sudah peneliti lakukan, hasil dan pembahasan dalam penelitian ini akan dijabarkan seperti berikut. Penelitian ini menggunakan 16 mahasiswa sebagai subjek penelitian. Agar mendapatkan grup dengan perlakuan hipnosis dan perlakuan self-hypnosis dilaksanakan dengan memakai oridinal pairing melalui sistem ABBA. Dasar dari pembagian ordinal pairing tersebut akhirnya didapatkan 4 grup, yang masing-masing grup itu melibatkan 4 orang atlet. Grup tertera adalah grup yang nantinya diberikan perlakuan dengan ketangguhan mental rendah (A1B1) dan ketangguhan mental agak rendah (A1B2). Grup yang akan diberikan perlakuan self-hypnosis dengan ketangguhan mental rendah (A2B1) dan agak rendah (A2B2). Langkah setelah itu dilakukan pemberian perlakuan hipnosis pada grup A1B1 dan A1B2 sebanyak 6 kali pemberian perlakuan, dan pada kelompok A2B1 dan A2B2 juga diberikan perlakuan sebanyak 6 kali.

Langkah pertama pada eksperimen ini, penulis membagikan instrument/alat untuk meneliti yang berbentuk angket dan modul kepada para atlet putra. Setelah itu atlet mengisi instrument sesuai dengan arahan dan penjelasan dari peneliti sebelumnya. Hasil dari 
pengukuran ditransformasikan dalam skor $\mathrm{Z}$ dan dilakukan perengkingan dari instrument angket dan modul tersebut. 8 ururtan yang rendah dan 8 urutan agak rendah dijadikan sebagai sampel. Setelah perlakuan tersebut telah selesai diberikan, selanjutnya dilakukan post-test terhadap subjek penelitian untuk mengetahui peningkatan konsentrasi pada atlet.

Tabel 4. Data Pre-tes dan Post-tes Treatment Hypnotheraphy

\begin{tabular}{lllll}
\hline \multirow{2}{*}{ Data } & $\begin{array}{l}\text { Ketangguhan } \\
\text { Mental }\end{array}$ & $\begin{array}{l}\text { Sumber } \\
\text { Variasi }\end{array}$ & Hipnosis & $\begin{array}{l}\text { Self- } \\
\text { Hypnosis }\end{array}$ \\
\hline \multirow{4}{*}{ Konsentrasi } & \multirow{2}{*}{ Rendah } & Pre test & 9,75 & 10,25 \\
& & Pos test & 14,50 & 19,75 \\
\cline { 2 - 5 } & \multirow{3}{*}{ Agak rendah } & Perubahan & 4,75 & 9,5 \\
& & Pre test & 11,5 & 11 \\
& & Pos test & 17,75 & 21,50 \\
& Perubahan & 6,25 & 10,5 \\
\hline
\end{tabular}

Tabel diatas memperlihatikan bahwa atlet dengan ketangguhan mental rendah diberi perlakuan hipnosis mengalami perubahan sebesar 4,75 dari rata-rata 9,75 meningkat menjadi 14,50. Sedangjan atlet dengan ketangguhan mental agak rendah dengan perlakuan hipnosis mengalami perubahan sebesar 6,25 dari rata-rata 11,5 meningkat hingga 17,75. Atlet dengan ketangguhan mental rendah yang diberi perlakuan self-hypnosis mengalami perubahan sebesar 9,5 dari rata-rata 10,25 meningkat hingga 19,75. Sedangkan atlet dengan ketangguhan mental agak rendah yang diberi perlakuan self-hypnosis mengalami perubahan sebesar 10,5 dari rata-rata 11 meningkat hingga 10,5.

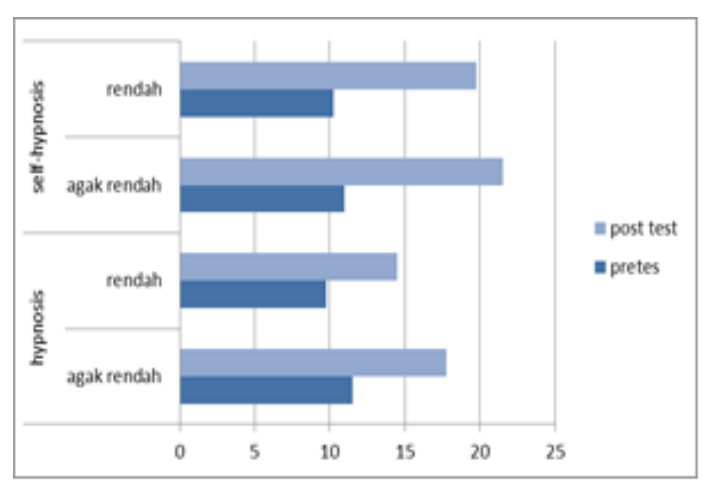

Gambar 1. Mean Pre-test dan Post tes

Sebelum melakukan analisa data maka penting untuk menguji terlebih dahulu bagian kenormalannya. Untuk menguji normalitas data dalam penelitian ini menggunakan shapiro wilk berbantuan software SPSS 16. Kemudian data dinyatakan berdistribusi normal jika ukuran signifikan $>0,05$. Perolehan dari uji normalitas data dapat dilihat pada tabel berikut:

Tabel 5. Perolehan Uji Normalitas

\begin{tabular}{rllllll}
\hline \multirow{2}{*}{ KELOMPOK } & \multicolumn{3}{l}{ Kolmogorov-Smirnov $^{\mathrm{a}}$} & \multicolumn{3}{l}{ Shapiro-Wilk } \\
\cline { 2 - 7 } NILAI PRETEST & .146 & 16 & $.200^{*}$ & .930 & 16 & .246 \\
\cline { 2 - 7 } POSTEST & .202 & 16 & .080 & .908 & 16 & .110 \\
\hline
\end{tabular}


Tabel diatas memperlihatkan bahwa nilai signifikansi dari data konsentrasi untuk data Pre-test yaitu 0,246 serta data tes akhir yaitu sebanyak 0,110. Data tersebut berdistribusi normal dikarenakan nilai signifikansi dari masing-masing data melebihi nilai 0,05.

Penelitian ini melakukan uji homogenitas dengan uji Levene Uji homogenitas dengan tujuan untuk melakukan uji kesamaan varian antara kelompok sampel 1 dengan kelompok sampel 2. Hasil dari uji homogenitas data kelompok sampel 1 dengan kelompok sampel 2 yaitu diperoleh hasil nilai uji f sebesar 0.186, derajat kebebasan (df1) 3 dan (df2) 12 dengan nilai signifikansi 0,904 . Nilai $F_{\text {hitung }}=0,186$ dari hasil uji homogenitas dengan nilai signifikansi $0,186>0,05$ yang berarti bersifat homogen dikarenakan bahwa varians data antara kelompok tidak berbeda nyata. Pengujian hipotesis dalam penelitian ini dilakukan berdasarkan dari hasil analisis data dan interaksi analisis varians. Untuk mengetahui perbedaan maka diperlukan uji Anava sebagai berikut.

Pembahasan yang akan dijabarkan dari hasil penelitian ini adalah sebagai berikut.

Pembahasan yang pertama, ada pengaruh baik perlakuan hipnosis dan perlakuan selfhypnosis terhadap konsentrasi atlet futsal Universitas Teknokrat Indonesia. Setelah dilakukan treatment dengan perlakuan hipnosis dan perlakuan self-hypnosis, terlihat bahwa terdapat perbedaan pengaruh terhadap konsentrasi atlet. Perbedaan ini ditunjukkan pada hasil perhitungan analisis varians yang diperoleh nilai signifikansi $=0,013$ dan taraf signifikasi 0,05 . Karna $0,013<0,05$ berarti terdapat adanya perbedaan pengaruh. Secara statistik ada pengaruh yang substansial dari kelompok hipnosis dan self-hypnosis terhadap konsentrasi atlet. Bahwa perlakuan hipnosis dan self-hypnosis pada atlet baik digunakan untuk meningkatkan konsentrasi atlet futsal Universitas Teknokrat Indonesia dilihat dari hasil yang ditunjukkan pada nilai rata-rata post test. Data hasil tes konsentrasi pada atlet dengan treatment hipnosis sebesar $48,71 \%$ sedangkan dengan treatment self-hypnosis sebesar 92,68\%. Menurut Supriyanto (2013) salah satu penentu keberhasilan treatment adalah sugestibilitas atlet untuk masuk ke alam bawah sadarnya. secara alamiah tingkat kesadarannya menembus faktor kritis sehingga evaluasi, penilaian, dan logika dari pikiran sadar dapat dilewati, namun secara singkat hipnosis bisa diketahui dalam meningkatkan kemampuan sugesti seseorang,. Seorang atlet dibantu oleh terapis atau pakar hipnosis adalah perlakuan saat pemberian treatment hipnosis. Keadaan seperti ini dilaksanakan supaya subjek (atlet) tersebut bisa dengan segera memasuki alam bawah sadar. Sedangkan padapemberian perlakuan self-hypnosis, atlet harus mampu mempengaruhi dirinya sendiri. Dalam (Sugara, 2013) self-hypnosis adalah sugesti diri atau self-suggestion, karena dasar saat untuk melaksanakan suatu penataan diri sendiri berarti sedang mensugesti atau mempengaruhi diri supaya sejalan dengan apa yang diharapkan.

Pembahasan yang kedua, tidak terdapat pengaruh yang sangat berarti antara ketangguhan mental rendah dan agak rendah terhadap konsentrasi atlet futsal Universitas Teknokrat Indonesia. Setelah dilakukan pengukuran mengenai ketangguhan mental rendah dan agak rendah dengan dibuktikan dengan respon yang menggunakan angket maka diperoleh nilai signifikansi $=0,130$ dan taraf signifikasi 0,05. Karna 0,130>0,05 artinya tidak berpengaruh. Dapat dilihat dari rata-rata perubahan dimana kelompok ketangguhan mental rendah sebesar 17,12 sedangkan pada ketangguhan mental agak rendah 19,62. Yang berarti pada atlet yang mengalami ketangguhan mental rendah mengalami perubahan menjadi ketangguhan mental agak rendah. Kemungkinan lain yang menjadi penyebab hasil skor pada setiap atlet menjadi tidak signifikan karna terlalu sedikitnya batas skala tingkat ketangguhan mental rendah dengan skala tingkat ketangguhan mental agak rendah.

Terlihat perubahan pada ketangguhan mental rendah untuk treatment hipnosis sebesar $18,59 \%$ dan ketangguhan mental rendah self-hypnosis sebesar 22,33\%. Sedangkan perubahan ketangguhan mental agak rendah treatment hipnosis sebesar $24,23 \%$ dan ketangguhan mental agak rendah sebesar 19,79\%. Dari data tersebut, dapat diartikan bahwa tidak terdapat 
perbedaan pengaruh yang dapat diterima dari ketangguhan mental rendah dan agak rendah. Ketiga, Tidak ada interaksi antara ketangguhan mental dan hypnotherapy terhadap konsentrasi atlet futsal Universitas Teknokrat Indonesia. Telah diketahui hasil dari masingmasing variabel terhadap konsentrasi atlet UKM Futsal dengan memakai uji anava kemudian mendapatkan nilai signifikan $=0,635$ dan taraf signifikasi 0,05. Karna 0,635 >0,05 berarti ketangguhan mental dan hipnoterapi tidak berinteraksi. Hal ini menunjukkan bahwa untuk meningkatkan konsentrasi atlet UKM Futsal tidak hanya dengan menggunakan angket ketangguhan mental saja, akan tetapi juga ditentukan oleh treatment atau perlakuan hipnosis dan self-hypnosis yang diberikan pada atlet.

Menurut Sugara didalam (Jamaliah et al., 2015) Semakin sering melakukan sugesti maka akan semakin efektif sugesti itu masuk kedalam pikiran bawah sadar merupakan sejumlah syarat yang harus dipenuhi supaya sugesti yang dilakukan benar-benar efektif dan permanen antara lain:. kedalaman emosi, visualisasi akan sugesti dan keseriusan dalam melakukan sugesti itu sendiri. Frekuensi yang dilakukan dalam melakukan sugesti diri. Apabila kecemasan yang tinggi datang pada seorang atlet dan menurun nya konsentrasi mengakibatkan atlet sullit untuk mengendalikan gerakan, main terlihat tidak bagus, dan kesulitan mengaplikasikan strategi yang sudah direncanakan sebab atlet merasa kebingungan apa yang harus dilakukan hingga hasilnya nanti mempengaruhi performa, maka dari itu penting untuk mencermati derajad kecemasan pada atlet ketika bertanding (Agus Mulyadi, Defri Mulyana, 2018). Penampilan atlet dipengaruhi oleh perasaan-perasaan subjektif diantaranya kegelisahan, ketegangan, kecemasan, ketakutan, dan kekhawatiran yang dapat menganggu terlaksananya pertandingan yang nantinya dihadapi seorang atlet (Larasati \& Prihatanta, 2019).

Penelitian yang dilakukan oleh (Supriyanto, 2013) pada saat start dalam renang, metode hipnoterapi dapat menjadi salah satu cara untuk meningkatkan konsentrasi terutama. Membantu seseorang menuju perubahan yang menyeluruh merupakan tujuan penggunaan metode hipnosis. Kondisi dimana seseorang kesadaran nya terfokuskan adalah arti dari hipnosis. kesemuanya itu merupakan penggunaan metode hipnoterapi. Didalam (Herani, 2018) menurut James, telah dikemukakan bahwa 50\% dari hasil pertandingan ditentukan oleh faktor psikologis yaitu mental. Aspek mental memiliki sumbangan sebesar $80 \%$ dan sisanya $20 \%$ merupakan aspek lain. Penelitian (Forastero, 2016) tentang mental toughness and competitive anxiety lainnya pada atlet futsal Universitas Surabaya karena dirasa bahwa setiap atlet memiliki tingkat kecemasan dalam bertanding yang berbeda-beda tergantung ketangguhan mental yang dimiliki oleh atlet tesebut. Menurut (Hakiki \& Kushartanti, 2018) pengalaman bertanding merupakan salah satu pengaruh dari psikologi seorang atlet. Apabila atlet semakin sering bertanding, maka kondisi psikologis nya akan lebih terlatih. Misalkan seorang petenis, semakin tinggi level petenis, maka psikologisnya akan semakin baik.

Clough, Earle, dan Sewell, 2002 bahwa sejumlah komponen yang diberi label sebagai 4C dari ketangguhan mental, yaitu: (1) Control, yaitu kemampuan untuk menangani banyak hal dalam satu waktu tertentu dan tetap berpengaruh (akan situasi) dibandingkan dengan merasa dipengaruhi. (2) Commitment, yaitu kemampuan untuk mempersepsikan ancaman sebagai peluang untuk pengembangan diri dan tumbuh subur didalam lingkungan yang selalu berubah. (3) Confidence, yaitu kemampuan untuk menegakkan keteguhan diri meski terjadi penurunan, dan tidak merasa terancam oleh pihak lawan. (4) Challenge, yaitu kemampuan untuk ikut serta lebih dalam pada tujuan yang sedang dikejar dan bekerja lebih giat untuk mencapainya meskipun selalu ada masalah (dalam L Crust, 2011). Pola kebiasaan, perasaan takut, perilaku, prestasi dan citra diri adalah lima kategori masalah yang sering terjadi pada 
anak (AW Gunawan, 2013). Untuk memanfaatkan hipnosis dalam kehidupan pribadi seseorang, self-hypnosis merupakan cara paling efektif digunakan.

Self hypnosis sangat berpengaruh terhadap konsentrasi atlet (Langenati, 2015). Eugene F Gauron dalam (Purnama, 2013) konsentrasi adalah suatu aktivitas pemusatan perhatian tertentu dan mengemukakan ciri-ciri konsentrasi diantaranya; tertuju pada suatu benda pada suatu saat, merupakan keseluruhan, perhatian selektif terhadap pemikiran tertentu dan tidak ada perhatian terhadap objek atau pemikiran lain, menenangkan dan memperkuat mental. Lasmono dan Wickens dalam Venstra berpendapat bahwa faktor usia mempengaruhi kemampuan konsentrasi karena kemampuan berkonsentrasi ikut berkembang sejalan dengan usia individu. Demikian pula halnya dibidang olahraga, bahwa konsentrasi atlet dapat ditingkatkan sejalan dengan usianya (Supriyanto, 2013). (Gunawan, 2010), memahami cara kerja pikiran, berikut hal-hal yang menunjukan bagian-bagian pikiran diantaranya yaitu bagian yang cuma mencatat dan menyimpulkan informasi dari tiap tragedi dan perasaan kita untuk waktu satu hingga satu setengah jam terakhir disebut dengan bagian conscious area. Alat pemersatu bangsa yang dapat membentuk karakter individu ataupun kolektif merupakan prinsip dari olahraga, serta mendinamiskan sektor-sektor pembangunan lainnya merupakan potensi yang dimiliki oleh olahraga. Peran dari pada olahraga adalah sebagai sebuah mesin character building and nation atau yang disebut dengan pembangunan karakter bangsa yang telah teruji, sebab olahraga memiliki fungsi membangun spirit kebangsaan. Baik fisik maupun mental sangat dibutuhkan demi tercapainya suatu prestasi yang maksimal dalam melakukan pembinaan atlet (Marsheilla Aguss, 2020).

Dalam penelitian ini langkah-langkah dan prosedur penelitian telah disusun sebaikbaiknya, tetapi dengan adanya keterbatasan, maka ada faktor yang tidak dapat dikendalikan, baik dari segi metode penelitian, pelaksanaan dilapangan, maupun keterbatasan dalam penyusunan dan hasil penelitian yang dicapai, dijumpai kelemahan dan keterbatasan yang sulit dihindari dalam penelitian ini. Beberapa keterbatasan yang dirasakan dalam penelitian ini yaitu yang pertama, keterbatasan kemampuan yang dimiliki oleh sampel penelitian sulit untuk mengikuti proses latihan. Kedua, sarana dan prasarana untuk melakukan proses pemberian perlakuan hipnoterapi yang kurang memadai dan kurang mendukung seperti penyediaan ruangan khusus yang lebih nyaman dan tertutup. Ketiga, faktor sugesti yang berbeda-beda pada setiap individu atlet sehingga mengakibatkan atlet sukar masuk ke alam bawah sadar nya dari ahli terapis pada atlet dalam kelompok hipnosis. Keempat, sulit diprediksi nya kesungguhan antara subjek yang satu dengan subjek lain dalam melakukan treatment dari awal sampai akhir eksperimen. Kelima, jumlah anggota sampel yang relatif sedikit, memungkinkan peluang terjadinya kekeliruan didalam analisis yang dilakukan. Hal ini dapat mempengaruhi hasil penelitian yang didapat.

\section{SIMPULAN}

Bersumber pada perolehan dari analisis dan pembahasan di atas, hingga memperoleh kesimpulan diantaranya sebagai berikut. (1) Ada perbedaan pengaruh antara perlakuan hipnosis dan perlakuan self-hypnosis terhadap konsentrasi atlet futsal Universitas Teknokrat Indonesia. Akan tetapi terjadi tingkat kemajuan dari data hasil tes konsentrasi pada atlet dengan treatment hipnosis mempunyai hasil yang lebih kecil dibandingkan dengan treatment self-hypnosis mempunyai hasil yang lebih besar. Berarti untuk treatment self-hypnosis lebih baik digunakan dibandingkan dengan treatment hipnosis untuk diberikan kepada atlet futsal.

(2) Tidak terdapat perbedaan pengaruh yang amat berarti diantara ketangguhan mental rendah dan agak rendah terhadap konsentrasi atlet futsal Universitas Teknokrat Indonesia. 
Tetapi terlihat perubahan pada ketangguhan mental rendah untuk treatment hipnosis yang sedikit agak rendah dibandingkan dengan ketangguhan mental rendah self-hypnosis. Sedangkan perubahan ketangguhan mental agak rendah treatment hipnosis lebih besar dibandingkan dengan ketangguhan mental agak rendah treatment self-hypnosis. Artinya Dari data tersebut, dapat diartikan bahwa tidak terdapat perbedaan pengaruh yang amat berarti dari ketangguhan mental rendah dan agak rendah.

(3) Tidak terdapat interaksi antara ketangguhan mental dan hipnoterapi terhadap konsentrasi atlet futsal Universitas Teknokrat Indonesia. Berdasarkan data hasil dari masingmasing variabel, telah diperoleh nilai signifikansi. Karna nilai signifikansi nya lebih besar dari taraf signifikan berarti ketangguhan mental dan hipnoterapi tidak berinteraksi secara signifikan. Untuk mengukur tingkat konsentrasi atlet tidak hanya dengan menggunakan angket ketangguhan mental saja, tetapi juga ditentukan oleh treatment hipnosis dan selfhypnosis yang diberikan pada atlet.

\section{DAFTAR PUSTAKA}

Agus Mulyadi, Defri Mulyana, J. (2018). Jurnal Pengabdian Siliwangi PELATIHAN HYPNOTHERAPY UNTUK MENURUNKAN TINGKAT KECEMASAN DAN MENINGKATKAN KONSENTRASI PADA ATLET BOLA VOLI SMK AL-HUDA Jurnal Pengabdian Siliwangi Volume 4 , Nomor 1, Tahun 2018 P-ISSN 2477-6629 E-ISSN 2615-4773. 4.

Alim, A. (2015). MENGATASI SULIT KONSENTRASI PADA ANAK USIA DINI. MEDIKORA. https://doi.org/10.21831/medikora.v0i1.4691

Ardini, F., \& Jannah, M. (2017). Mental Thoughness dan Competitive Anxiety Pada Atlet Bola Voli. Character: Jurnal Psikologi Pendidikan, 04(2), 1-5.

AW Gunawan. (2013). Hypnotherapy For Children. In PT Gramedia Pustaka Utama.

Bolla, I. N., Ropei, O., \& Pratama, A. (2018). Bulutangkis Di Unit Kegiatan Mahasiswa Universitas Pendidikan Indonesia. 1(1), 21-30.

Forastero, A. (2016). Mental Thoughness dan Competitive Anxiety Pada Atlet Futsal. Universitas Surabaya, 5(1), 1-8.

Gunarsa, D. S. (2012). Psikologi Remaja. In BPK Gunung Mullia.

Gunawan, A. W. (2010). Hypnotherapy For Childrean: Cara Mudah dan Efektif Menerapi Anak. In PT Gramedia Pustaka Utama.

Hakiki, Q. S., \& Kushartanti, B. . W. (2018). Terhadap Penyembuhan Cedera Ankle Pasca Effect of Warm Compresses and Warm Compresses on Healing of Post Manakulasi Ankle Injuries in. XVII(2), 136-144.

Halim, S. (2012). 1 HARI PINTAR MAIN FUTSAL.

Hasibuan, H. M. (2016). ANALISIS TACTICAL INDIVIDUAL DEFENCE (BLOCK DAN INTERCEPT) TIM FUTSAL UNIVERSITAS NEGERI JAKARTA PADA UGM FUTSAL CHAMPIONSHIP 2016. In Prosiding seminar dan lokakarya FIK UNJ (pp. 240-246). 
Herani, I. (2018). MENTAL THOUGNESS DENGAN PEAK PERFORMANCE PADA ATLET RENANG. Jurnal Ilmu-Ilmu Sosial, 10(2), 198-212.

Jamaliah, N., Sugiharto, \& H, O. W. K. (2015). Journal of Physical Education and Sports KONSENTRASI ATLET PUTRI CLUB PEKERJAAN UMUM ( PU ) DELI. Journal of Physical Education and Sports, 4(2), 136-140.

L Crust, P. C. (2011). Developing Mental Thoughness: From Research To Practice. Jurnal Of Sport Psy Choogy In Action, 2(1), 21-32.

Langenati, R. (2015). Pengaruh Self-Hypnosis Terhadap Konsentrasi Pada Atlet Senam Artistik. Unesa, 3, 1-6.

Larasati, D. M., \& Prihatanta, H. (2019). Pengaruh Terapi Musik Terhadap Tingkat Kecemasan Sebelum Bertanding Pada Atlet Futsal Putri. Medikora, 16(1), 17-29. https://doi.org/10.21831/medikora.v16i1.23476

Lhaksana, J. (2011). Taktik \& Strategi FUTSAL Modern.

Maheswari, A. P. (2019). Hubungan Antara Ketangguhan Mental Dengan Peak Performance Pada Atlet Taekwondo.

Marsheilla Aguss, R. (2020). PERSEPSI ATLET FUTSAL PUTRA UNIVERSITAS TEKNOKRAT INDONESIA TERHADAP HIPNOTERAPI DALAM MENINGKATKAN KONSENTRASI SAAT BERTANDING. Jurnal Penjaskesrek, 7(2), 274-288.

Purnama, S. K. (2013). Latihan Imagery. Jurnal Iptek Ola, 3(2), 103.

Purnama, S. K. (2016). Perbedaan Pengaruh Tingkat Kesuliltan dan Tinggi Badan Terhadap Hasil Tembakan Free Throw Bola Basket. Indonesian Journal Sports Science, 13(1), 1689-1699.

Sa'roni, A. S., \& Graha, A. S. (2019). EFEKTIFITAS MASASE TERAPI CEDERA OLAHRAGA TERHADAP NYERI TUMIT DAN NYERI OTOT TIBIALIS PADA ATLET FUTSAL SMA NEGERI 1 CIAMIS. MEDIKORA. https://doi.org/10.21831/medikora.v18i2.29197

Sartono, S., Suryaman, O., Hadiana, O., \& Ramadan, G. (2020). Hipnoterapi untuk kecemasan: sebuah uji coba pada pemain sepakbola. Jurnal SPORTIF: Jurnal Penelitian Pembelajaran, 6(1), 216-225. https://doi.org/10.29407/js_unpgri.v6i1.13832

Sugara, G. S. (2013). TERAPI SELF-HIPNOLSIS (SENI MEMPROGRAM ULANG PIKIRAN BAWAH SADAR). In PT INDEKS.

Supriyanto, A. L. (2013). Penggunaan Metode Hypnoterapi Untuk Meningkatkan Konsentrasi Saat Start dalam Renang. Jurnal IPTEK Olahraga, 15(9), 111. 